American J. of Engineering and Applied Sciences 2 (4): 750-753, 2009

ISSN 1941-7020

(C) 2009 Science Publications

\title{
Steel Piling Corrosion Management of Al-Zubare Harbor
}

\author{
${ }^{1}$ Mohammed H. Hafiz and ${ }^{2}$ Hemin M. Mohyaldeen \\ ${ }^{1}$ Department of Production and Metallurgy Engineering, University of Technology, Baghdad, Iraq \\ ${ }^{2}$ Faculty of Mechanical Engineering, University of Malaysia Pahang, Kuantan, Malaysia
}

\begin{abstract}
Problem statement: Damage due to corrosion is a significant problem worldwide. Countries around the world have estimated that the cost of corrosion to their national economies to be 3-4\% of their gross national product. Approach: Design and implementation a new steel piling of the Corrosion Management Program (CMP) in Al-Zubare harbor. Corrosion management algorithm can be divided into three major phases. Phase 1 of the program is the programmatic assessment of the project. Phase 2 of the program involves physical assessment and actual remediation. Phase 3 of the program mainly deals with future monitoring of the repaired structure. Results: The CMP included activities performed to mitigate corrosion, to repair corrosion-induced damage and to replace the structures that are badly corroded. Installation and maintenance requirements are identified. Conclusion: The data was collected from the tide table for Al-Zubare Harbor in the year 2004. The highest tide of the year would fall on 17 October 2004 at 1.05 am with level $3.5 \mathrm{~m}$, while the lowest tide of the year would fall on 3 July 2004 at 5.13 am with level $0 \mathrm{~m}$. The detection results show that this program is feasible and effective.
\end{abstract}

Key words: Corrosion, management, steel piling

\section{INTRODUCTION}

Corrosion and in particular corrosion of metal structures, is a problem that must regularly be addressed in a wide. Variety of areas, for example, in the automotive industry, metal parts are often plated or coated to protect them from road salt and moisture in hopes of increasing their longevity. Indeed, many traditionally metal parts are currently being with polymeric components, which are not only lighter and perhaps more cost effective to produce, but are generally impervious to electrochemical corrosion often experienced by metals.

In recent years, an extensive amount of research work has been carried out in order to better understand and control several of the most important deteriorating mechanisms such as alkali aggregate reactions, freezing and thawing and corrosion of embedded steel. In particular, much work has been carried out on corrosion of embedded steel, which represents the greatest threat both to the safety and economy of the structures. Never before has so much basic information and knowledge about concrete durability been available. The great challenge to the professional society is, therefore, to utilize and transform more of this existing knowledge into good and appropriate engineering practice ${ }^{[1,2]}$.
Cathodic prevention is an electrochemical technique aimed at preventing corrosion initiation in reinforced concrete structures subjected to chloride penetration, as slabs and piles of bridges in the presence of de-icing salts and structures in marine environment ${ }^{[3]}$. Moreover, the cathodic reaction at the steel surface leads to the production of alkalinity and thus avoids the local $\mathrm{pH}$ decrease involved in pitting corrosion; also the ion migration is expected to play a beneficial role in reducing the chloride concentration in the vicinity of the steel surface ${ }^{[4,5]}$.

Theoretical background: Corrosion and in particular corrosion of metal structures, is a problem that must regularly be addressed in a wide. Variety of areas, for example, in the automotive industry, metal parts are often plated or coated to protect them from road salt and moisture in hopes of increasing their longevity. Indeed, many traditionally metal parts are currently being with polymeric components, which are not only lighter and perhaps more cost effective to produce, but are generally impervious to electrochemical corrosion often experienced by metals.

Even with the proper selection of base metals and well-designed systems or structures, there is no absolute way to eliminate all corrosion. Therefore, corrosion

Corresponding Author: Mohammed .H .Hafiz, Department of Production and Metallurgy Engineering, University of Technology, Baghdad, Iraq 
protection methods are used to additionally mitigate and control the effects of corrosion. Corrosion protection can be in a number of different forms/strategies with perhaps multiple methods applied in severe environments. Forms of corrosion protection include the use of inhibitors, surface treatments, coatings and sealants, cathodic protection and anodic protection.

Corrosion mechanism of steel in seawater: On steel piling in seawater, the more chemically active surface areas (anodes) are metallically coupled through the piling itself to the less chemically active surface areas (cathodes) resulting in a flow of electricity and corrosion of the anodic areas. General surface roughening occurs when these local anodic and cathodic areas continually shift about randomly during the corrosion process. Sometimes these active local areas do not shift position end, therefore, the metal suffers localized attack and pitting occurs. In general, the depth of pitting is related to the ratio of the anodic sites to the area of cathodic site in contact with the electrolyte (seawater), the smaller the anode area relative to the cathode area, the deeper the pitting.

Zones of corrosion of steel piles: Examination of corroded marine piles reveals several distinct areas of attack. It is convenient to dive these areas into five zones, each having a characteristic corrosion rate as shown in Fig. 1.

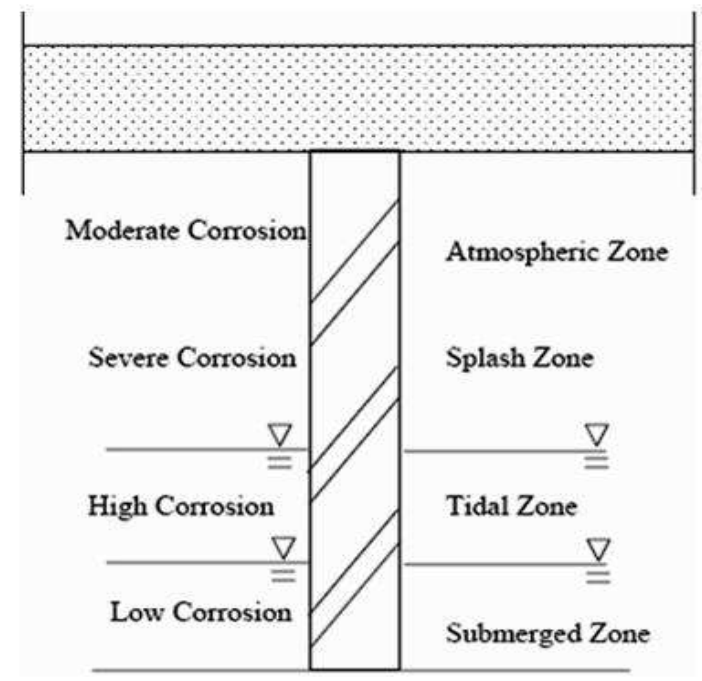

Fig. 1:Typical corrosion regions of a steel pile in marine environment

\section{MATERIALS AND METHODS}

A case study has been carried out on a concrete repair of a shipping yard that was corroded after approximately 25 years of service life. The client involved in the reconstruction work is Al-Zubare. Figure 2 shows the view of the deck and steel piling of the structure.

They were nominated as the main contractor for the repair work of Al-Zubare Dolphin C to Dolphin D at Quay 2 and Quay 3. Subsequently, they awarded the contract and the work of rehabilitations begins commencement on February 2004.

At that point, a few alternatives in order to repair the docks which were severely corroded due to lack of protective measures taken during construction and also due to daily exposure to corrosive environment. Rate of corrosion increased when tide is high. Continuing ingression of corrosive agents such as chloride from seawater has prompted to come out with an alternative which will provide long term protection. However, before deciding on the methods to be applied, a conceptual and feasibility studies has been carried out. Typically, corrosion management can be divided into three major phases.

Phase 1 of the program is the programmatic assessment of the project. This phase is the planning stage for a corrosion management program to take place. It initiates the program to be implemented on structures that are found to be under the threat of corrosion. For the planning stage, three main requirements are sought, namely the strategy, budget and schedule needed to overcome the problem raised from corrosion of reinforcement. This is seen as an important part for an effective management program as feasibility studies are normally conducted to determine the serviceability of the structure after treatment.

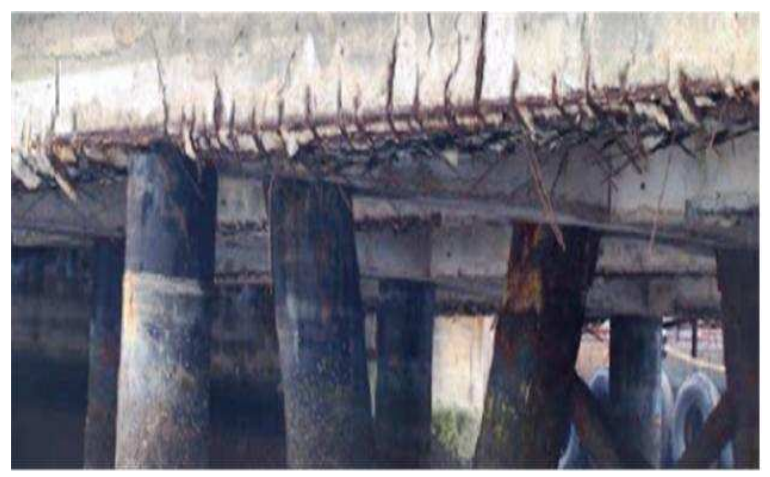

Fig. 2: View of the deck and steel piling 
Phase 2 of the program involves physical assessment and actual remediation. Inspections for severity of corrosion are conducted in this phase to determine what strategy or methods are most suitable to be applied. Development of corrosion control strategy would present more option to the management program. Remedial work would be carried out once the proper strategy has been recognized.

Phase 3 of the program mainly deals with future monitoring of the repaired structure. Currently and historically, most of the corrosion control programs are driven by response to incident or urgent need, rather than systematically identifying and managing the existing resources. This can be overcome by implementing internal or external monitoring system using current technology practiced in oil and gas industries. The overall flowchart for an effective corrosion management program is as shown in Fig. 3.

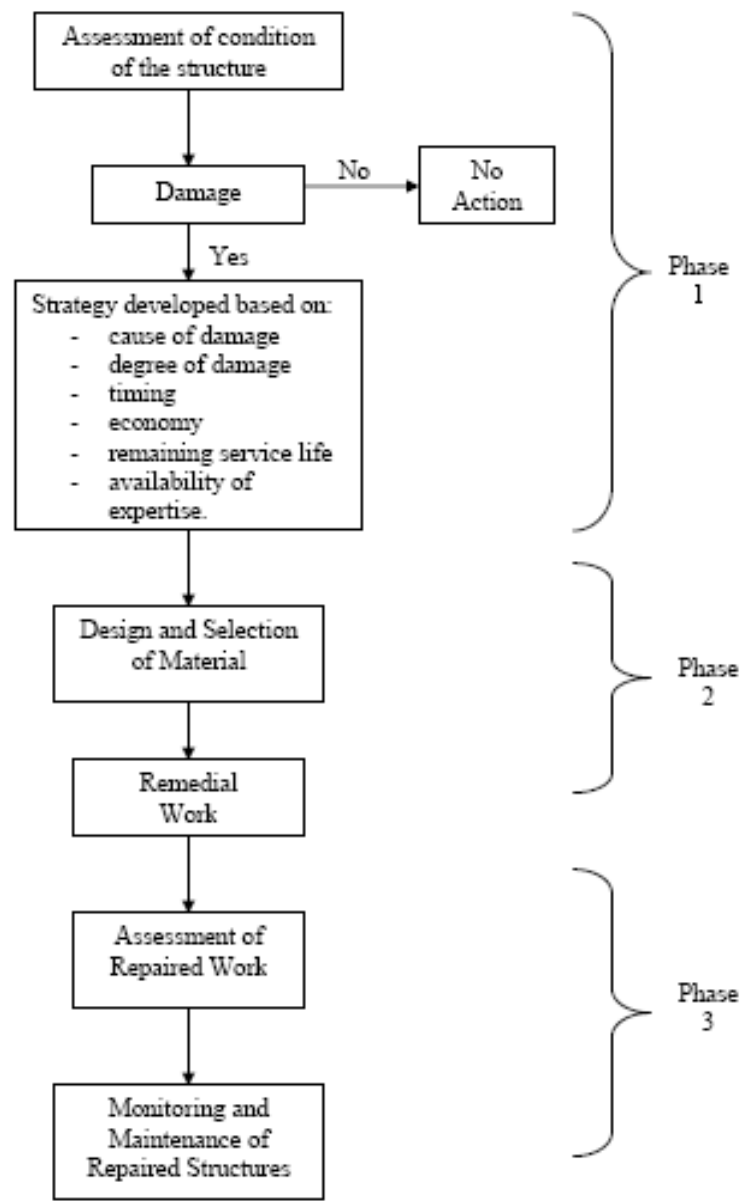

Fig. 3: Corrosion management program

\section{RESULTS}

Before a visual inspection is carried out, primary data was required to plan for a systematic visual inspection. Those data being obtained included the Tide Table from Maritime Department and the layout plan of the steel pipe pile between Dolphin C and Dolphin D. From the tide table for Al-Zubare Harbor in the year 2004, the highest tide of the year would fall on 17 October 2004 at 1.05 am with level $3.5 \mathrm{~m}$, while the lowest tide of the year would fall on 3 July 2004 at 5.13 am with level $0 \mathrm{~m}$.

Carbon and low alloy steels are susceptible to uniform atmospheric corrosion while stainless steels are considered resistant. Figure 4 shows data collected on various carbon and low alloy steels tested for uniform corrosion in a real atmospheric environment. The graphs clearly show the decline in corrosion rate over time, with the exception of the severe marine environment.

The corrosion rate of steels in acids depends upon the composition and concentration of acid, as well as temperature. The corrosion rate of steels in hydrochloric acids will continuously increase with increasing acid concentration. In sulfuric acids, however, the corrosion rate increases until a level of concentration where passivity is reached, Fig. 5. If the passive film is damaged by mechanical or chemical means, the corrosion rate will significantly increase in concentrated solutions.
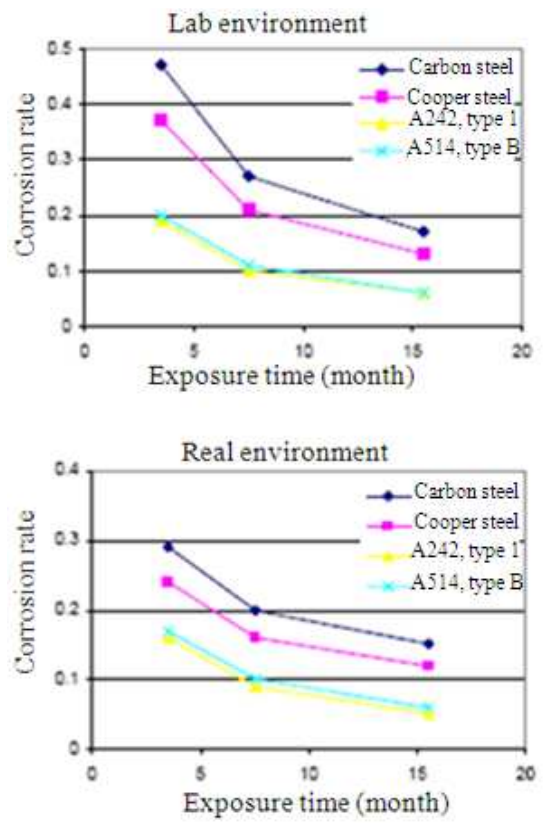

Fig. 4: Uniform corrosion of steels in various atmospheric environments 


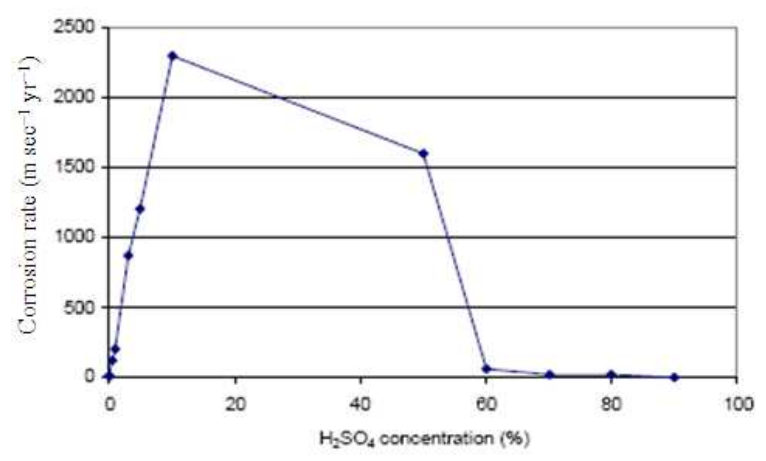

Fig. 5: Uniform corrosion of carbon steel by sulfuric acid at room temperature

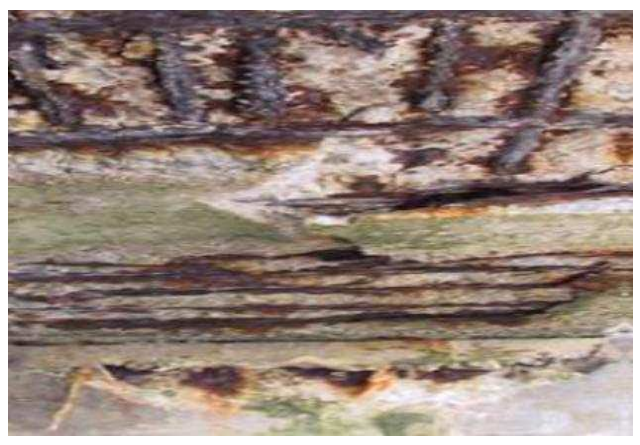

Fig. 6: Concrete cover was seen disintegrated from beams

\section{DISCUSSION}

The corrosion characteristics and properties of metals come from field experience and extensive testing in natural, simulated and accelerated environments. The results of testing are used to rate materials and determine what alloying and heat treatments are beneficial to corrosion resistance. Field experiences, as well as test results, are used to document susceptibilities of materials under specific conditions.

Attack of concrete by seawater can be of various types: superficial erosion caused by waves of tides, swelling caused by crystallization of salts, chemical attack by salt dissolved in the water. The most critical part of the structure is the tidal and splash zones which happened to be the deck. Cyclic drying and capillary suction occur in the concrete just above sea level, dissolved salts were carried by water into the concrete. Evaporation of the salts caused this salt to crystallize in the pores, producing stresses that can cause micro cracking which explains the reason of concrete spelling off the structure. Concrete structures which are near but not exposed to seawater suffer similar fate through wind depositing salt aerosols. Figure 6 shows the disintegration of concrete from the beams.

\section{CONCLUSION}

A routine maintenance work is needed to be carried out for those steel pipe piles in order to make sure the effectiveness as a load transfer structure to the hard strata. However, as for the deck, the reinforcements are needed to be replaced as the strength of the steel would reduce significantly in near future. Protective measures were also required to be introduced to prevent the ingress of corrosive elements and thus prolong the service life of the structure.

\section{ACKNOWLEDGEMENT}

The researchers thank the Department of Production and Metallurgy Engineering, of WHO that funded the project with resources received for research from university of technology.

\section{REFERENCES}

1. Barnes Richard, 2007. Corrosion of Steel in Concrete: Understanding, Investigation and Repair. 2nd Edn., John P Broomfield Publisher: Taylor and Francis, ISBN: 978-0-415-33404-4, pp: 240.

2. Bertolinia, L., F. Bolzonia, M. Gastaldia, T. Pastoreb, P. Pedeferria and E. Redaellia, 2008. Effects of cathodic prevention on the chloride threshold for steel corrosion in concrete. Electrochimica Acta, 54: 1452-1463. DOI: 10.1016/j.electacta.2008.09.033

3. Chandler, K.A. and D.A. Bayliss, 1985. Corrosion Protection of Steel Structures. Elsevier Applied Science, ISBN: 0853343624.

4. Luca Bertolini, Bernhard Elsener, Pietro Pedeferri and Rob Polder, 2004. Corrosion of Steel in Concrete: Prevention, Diagnosis, Repair. WileyVCH., ISBN: 978-3-527-30800-2, pp: 409.

5. Roberge, P.R., 1999. Handbook of Corrosion Engineering, McGraw-Hill Professional, ISBN: 0070765162. 